\title{
A Duration Model Analysis of Consumer Preferences and Determinants of Video Game Consumption
}

\author{
Daniel Kaimann ${ }^{1}$, Nadja Stroh-Maraun ${ }^{1}$, Joe Cox² \\ ${ }^{1}$ University of Paderborn, Faculty of Business Administration and Economics \\ ${ }^{2}$ University of Portsmouth, Faculty of Business and Law
}

January $25^{\text {th }}, 2018$

\begin{abstract}
Despite the enormous revenues generated by the video game industry in recent years, relatively little research has been undertaken into consumer preferences and the determinants of video game consumption. This study addresses this deficiency through the analysis of data from a popular online video game that includes historic behavioural information for 1,408 consumers participating in 728,811 unique rounds of gameplay. We analyse these data with the goal of estimating determinants of the aggregate amount of time that a consumer spends playing the game. Through the estimation of duration models, we show that less experienced consumers are less likely to continue playing the game at any given point, possibly due to having mastered the game and becoming bored. However, we also find that consumers tend to play the game for longer periods when using a wider range of character roles and vehicles, implying that a consumer's interest can be maintained through exposure to greater variety. Our results represent the first such evidence on in-game consumer preferences, which has important implications for video game consumption through optimisation of gameplay experiences to satisfy these preferences.
\end{abstract}

Keywords: Preferences; Video game industry; Duration model

JEL Classification C41; C55; D12; L82 


\section{Introduction}

The video game industry represents one of the largest individual components of the market for toys and leisure products. In 2015, the North American video games industry was valued at US\$17 billion and is predicted to grow to more than US\$20 billion by 2020 (Statista 2017). The lifetime sales revenues of some individual video game titles meet or exceed those of even the most well-known movie blockbusters, including Star Wars, Harry Potter and Lord of the Rings (Activision Publishing Inc. 2011). In the context of these significant and increasing industry revenues, it is important to understand consumer preferences and motivations for video game consumption. It is widely argued that video games represent a form of "playful consumption" (Abbasi and Jamak 2017), which is primarily motivated by enjoyment and other hedonic factors.

The usage and purchase of video games of various genres such as action, sports or Massively Multiplayer Online Roleplaying Games (MMORPGs) is increased if the game offers self-congruity, which measures the brand's or game's influence on the consumer (Davis and Lang 2013). Other factors, such as selfefficacy (Davis and Lang 2011) or perceived control (Davis and Lang 2012), also affect the usage and purchase decision for some game genres. Indeed, hedonic motivations appear to better explain variations in usage and purchase intentions among video game consumers compared with more utilitarian factors such as ease of control or complexity (Davis et al. 2013).

Studies that have attempted to develop formal scales to measure the motivations to play games have tended to be based upon a range of underlying psychological theories and frameworks (De Grove et al. 2016). One such framework is 'self-determination theory', which argues that video gaming satisfies a number of universal human needs including competence, relatedness and autonomy (Przybylski et al. 2010; Tamborini et al. 2010). An alternative is 'social cognitive theory' (Bandura 2001), which argues that human behaviour is driven by a process 
of self-regulation involving observation, reflection and adjustment. Viewed in this way, sustained consumption of media and video games might be a consequence of deficiencies in the self-regulation process, which in turn leads to habit formation (LaRose et al. 2003; Lee and LaRose 2007). The importance of optimal interaction between the player, narrative and gameplay elements in motivating consumption has also been highlighted by several authors, notably including Buchanan-Oliver and Seo (2012) and Kuo et al. (2017).

Despite the relatively wide variation in the use of underlying theories and methodologies outlined above, a majority of studies into the motivation and behaviours of video game players from the consumer psychology literature choose to adopt the 'uses and gratifications' (U\&G) model. This framework was first used to explain variation in media use among consumers by Weibull (1985). In this model, consumers are drawn to the consumption of particular media as a result of a number of potential uses that satisfy their needs, while consumer reaction or 'gratification' in turn influences the continued motivation to consume. For example, in an early study Holbrook et al. (1984) models consumer enjoyment of games by focusing on the relationship between player performance, emotions and personality, finding that performance depends on a consumer's playing history (skill and experience) as well as their individual characteristics.

A number of studies have attempted to use the U\&G model framework to measure motivations among video game consumers, often through the use of surveys. These include Yee (2006), who uses the 'principal component analysis' (PCA) on the basis of survey responses from 3,000 players of MMORPGs. The study finds that consumer motivations can be broken down into three core factors that are consistent with the U\&G model; namely achievement (including competition and advancement), immersion (discovery, customisation) and social interaction. Similarly, Jansz and Tanis (2007) undertake a survey of around 750 online first-person shooter (FPS) gamers. Using a principal component analysis, they find that the main motivations for consumption are competition, interest, enjoyment, fantasy, 
social interaction and excitement, with competition and social interaction found to be the strongest. Additionally, Wallenius et al. (2009) find that a combination of instrumental (i.e. to learn, develop skills, experience new things) and ritualised (i.e. to pass time, recover, escape) motives best explain the consumption of video games among a sample of Finnish adolescents.

Our study contributes to the consumer behaviour literature by using the U\&G model framework to investigate preferences for video game consumption in the context of a popular online multiplayer title. A major limitation of the empirical analysis undertaken by many of the studies cited above is a reliance on stated preferences and behaviours through the use of survey data. Our study overcomes this limitation by using motivational elements from the U\&G model framework to analyse consumer continuation on the basis of real behaviours observed in an online gaming environment. Second, many studies into motivation fail to account for the problem of endogeneity between the preferences and actions of video game consumers. This problem might occur as a result of such issues as simultaneous causality and omitted variable bias, which limits the extent to which regression analysis can be employed to explore such relationships. To overcome these concerns, we employ duration modelling to help ensure exogeneity in our empirical modelling. In using this approach, we aim to address the following research question:

What are the specific, observable determinants of variations in the aggregate amount of time that consumers remain engaged with a multi-player online game?

Our study makes use of real, in-game data provided by the Wharton Customer Analytics Initiative (WCAI) and a major international video gaming company. The dataset relates to a popular online multiplayer first-person shooter game available for two home consoles (Sony Playstation 3 and Microsoft Xbox360) and PC. Over the course of their engagement with this multi-player online video game, consumers participate in a series of discrete gameplay instances or 'rounds'. Within 
a game round, two teams battle against one another with the primary objective varying between game modes. The common secondary objective for all types of gameplay round is to kill opponents and avoid being killed. In addition, the game features different vehicles that can be used in each round, ranging from armoured and unamoured land vehicles to jets, boats and helicopters. Players also select a 'role' by adopting a particular player class (i.e. assault, engineer, support, and recon) with a particular set of gameplay attributes and abilities and are able to change their role upon respawning. The dataset consists of historic observations covering 1,408 consumers participating in 728,811 unique game rounds, i.e. specific gameplay instances involving two or more consumers interacting simultaneously. We suggest that consumer preferences will affect the aggregate amount of time consumers spend interacting with a given multi-player online video game.

The remainder of the paper is organised as follows. The following section outlines the key theory and literature that leads to the development of our research hypotheses. This is followed by a section where we provide a more detailed description of our data and empirical models. Finally, we present a section containing an analysis of our findings followed by a discussion of the results, including a number of important managerial implications.

\section{Theoretical Background and Hypotheses}

Many studies use a framework that is influenced by or closely resembles the U\&G model. To model the behaviour of entertainment software consumers, Sherry et al. (2006) identify a number of traits (i.e. arousal, competition, challenge, diversion, fantasy, social interaction) that are used to model variations in the self-reported number of hours spent playing video games weekly among a sample of students. Challenge, competition and social interactions are found to be the strongest predictors of variation in number of hours played per week. A study by Chang et al. (2006) also models the factors that explain continuation of online gaming activ- 
ity among consumers, identifying distinct differences between game adopters and non-adopters in terms of gender, perceived need of passing time, video game use and internet use. Wu et al. (2010) find continuation of gameplay to be strongly motivated by personal traits (i.e. preferences for achievement, enjoyment and social interaction) as well as service mechanisms (i.e. fairness, security and incentive). However, an important limitation of this and other studies is the reliance on selfreported data gathered via surveys. The use of survey data may lead to significant biases given their self-reported nature, as well as the possibility that survey questions would be interpreted differently by individual participants. In addition, as survey participation is voluntary, the self-selective nature of respondents may lead to a non-representative sample of the studied population.

On the basis of the findings of these studies, we contend that several observable characteristics are likely to affect preferences for the consumption of online multiplayer video games. We study these relationships by investigating the aggregate amount of time a consumer remains engaged with a multi-player online video game. We interpret longer aggregate durations of engagement as a proxy for positive game experience and thus broadly indicative of preferences for video game consumption. Our study therefore addresses a significant gap in the literature by analysing consumer retention on the basis of the observed behaviours of real players in an online gaming environment, rather than relying exclusively on stated preferences. We argue that consumer preferences are likely to be influenced by three key factors: demographics, experience and skills, and in-game variety. We outline the relevant theory and evidence relating to these factors in Figure 1, ultimately leading to the presentation of specific research hypotheses to be tested as part of our empirical analysis.

[Figure 1 about here] 


\section{Demographic Factors and Consumer Characteristics}

A number of prior studies suggest that variations in demographic characteristics (e.g. age, gender and/or nationality) are likely to play a significant role in determining consumer preferences. A study by Yee (2006) surveys a sample of 3,000 consumers of online games, identifying three distinct consumer preferences: achievement (including competition and advancement), immersion (discovery, customisation) and social interaction. The study also shows that males typically score higher on the achievement component versus females, who tend to score higher on the social component. However, the relative focus on achievement is also found to decline significantly with age, with the probability of playing video games decreasing with age at a diminishing rate (Borowiecki and Prieto-Rodriguez 2015). The same authors also find that a typical video game player is a young male who lives in an urban area and has access to new technologies. Cox (2008) highlights the importance of geographical grouping of countries that might be due to shared cultural attributes with the common use of video games systems. Thus, we formulate the following research hypotheses relating to the relationship between the aggregate amount of time each consumer spends playing the game (our dependent variable) and a range of explanatory variables reflecting demographic factors.

H1: Consumer preferences for multi-player online video game consumption vary significantly with demographics. Specifically:

H1a: The aggregate amount of time spent playing will associate negatively with age, although at a diminishing rate.

H1b: Female consumers will spend a smaller aggregate amount of time playing compared with male consumers.

H1c: The aggregate amount of time spent playing will vary with country of residence. 


\section{Experience and Skills}

Using an experimental approach, Liu et al. (2013) study the skill levels of consumers in competitive video games, finding that consumers play longer and participate in more rounds when they are matched with similarly skilled opponents. The measurement of consumer skill is highly dependent upon the context of the specific game under analysis. In our analysis of data from a team-based first person shooter game based heavily around player-versus-player combat, the difference between kills (the number of times that a consumer defeats/kills an opposing consumer in each round) and deaths (the number of times that a consumer is defeated/killed by an opposing consumer), averaged over the period of time spent playing, represents the most straightforward means by which to assess individual skill levels in a single metric. Additionally, consumers are likely to be at least partly motivated by the achievement of other in-game objectives, such as scores awarded for defending strategically important locations, supporting other consumers in their team with health or ammunition, or guarding a flag. Thus, we formulate additional hypotheses concerning the relationship between the aggregate amount of time spent playing the game (our dependent variable) and a range of variables reflecting consumer experience and skill. More specifically, experience is measured using a combination of what we call the 'rookie effect' (the difference in days between the date of the game's release and the day on which the individual con-

sumer first started playing) and the rank that the player has achieved in the game. Additionally, a player's skill is measured in terms of kills-deaths and non-combat scores (averaged per second as outlined above).

H2: Consumer preferences for multi-player online video game consumption vary significantly with gaming experience and skills. Specifically:

H2a: Consumers with more experience will play for longer aggregate periods compared with consumers with less experience.

H2b: The aggregate amount of time spent playing will associate positively 
with the difference between the number of kills and deaths achieved in any given gameplay round, averaged over the length of time spent participating in that round.

H2c: The aggregate amount of time spent playing will associate positively with the non-combat score achieved in any given gameplay round, averaged over the length of time spent participating in that round.

\section{Variety}

Using a principal component analysis, Jansz and Tanis (2007) survey a sample of 750 online first-person shooter gamers to investigate the principal motivations for participation. Among the identified factors of competition, interest, enjoyment, fantasy, social interaction and excitement, they find the most powerful variety motivators for video game consumption to be competition and social interaction. In modern multiplayer video games, consumers can decide on a wide variety of different roles, game modes, and levels (maps) in which they want to participate. Following the study of Jansz and Tanis (2007), we assume that consumers prefer a complex combination of these gaming choices to enhance the variety of gameplay experience. We therefore propose the following hypothesis relating to the relationship between the aggregate amount of time spent playing the game (our dependent variable) and a range of variables reflecting the degree of variety experienced by the consumer over the duration of their engagement with the game. Specifically, these include measures of variation in the roles adopted by the consumer over time, given that consumers can adopt different roles allowing them to perform specific tasks, such as an Engineer who can repair vehicles or a Recon who can gather information to support other consumers. We also measure variation in the number of vehicles used over time (consumers can enter and control a variety of vehicles, including tanks, boats, helicopters etc.), as well as variation in the the gameplay modes adopted over time (consumers can elect to play various different modes of the game with differing goals, such as Team Death Match or 
Conquest).

H3: Consumer preferences for multi-player online video game consumption vary significantly with in-game variety. Specifically:

H3a: The aggregate amount of time spent playing will associate positively with variety in the consumer's use of roles over time.

H3b: The aggregate amount of time spent playing will associate positively with variety in the consumer's use of vehicles over time.

H3c: The aggregate amount of time spent playing will associate positively with variety in the consumer's use of game modes over time.

\section{Control Variables}

We also include a number of control variables to account for a range of other observable features and characteristics that might plausibly affect the aggregate amount of time consumers spend playing the game. These include individual preferences for hardware platforms, a cohort control, the consumer's lifetime purchase amount and the date on which they set up their online account with the publisher. It should be noted that the account sign-up date is not specific to this particular game and can be used when participating in multiple games released by the same publisher. This particular variable therefore is distinct from our other measures of player experience, which are directly related to the specific game being studied. While we expect that the aggregate amount of time spent playing the game will vary in accordance with these control variables reflecting the features of successive gameplay rounds, the nature of each effect is ambiguous a priori.

\section{Data Description and Model}

This study aims to establish the relationship between a range of consumer and round-specific characteristics and the aggregate amount of time consumers con- 
tinue playing the game. Our individual consumer-level data consists of information on all individual rounds played by 1,408 consumers who belong to two cohorts of around 700 consumers each. The first cohort began playing within the first month after the product launch in October 2011, while the second cohort began playing three months later in January 2012. The sample covers all rounds played by these consumers over a period of 18 months, meaning we have basic and historical behavioural data for each of these 1,408 consumers, resulting in data covering 728,811 unique gameplay rounds. Our dataset contains detailed information on each consumer's home country, age, gender and the length of time they have owned and played the game. For each consumer, we have round-specific data concerning their performance, e.g. the number of points earned, the role they played and which additional features of the game they used.

We begin an initial analysis of the data by taking a look at the derivation of our dependent variable, i.e. the aggregate amount of time spent playing the game for each consumer measured in seconds. This measure is effectively the sum of the amount of time spent participating in individual gameplay rounds. This round duration appears to be dominated by a small number of excessive outliers, e.g. the longest recorded duration of a single round is alleged to be greater than 26 hours. We therefore elect to winsorize the data by setting values above the 99th percentile at the 99th percentile. A kernel density function showing the overall duration of rounds following this procedure can be found in Figure 2 . It can clearly be seen that the distribution of this variable remains relatively long-tailed, even after the data have been winsorized. Specifically, the data suggest that, while a majority of gameplay rounds last less than 30 minutes, there are a disproportionately small number of rounds that last for much longer periods of time; even approaching 2 hours in some cases.

[Figure 2 about here]

As already mentioned, we generate the dependent variable by summing up 
the winsorized round durations. As our dataset consists of a panel reflecting observations for each consumer in each gameplay round, our dependent variable is calculated on a dynamic (round-by-round) basis. Around $50 \%$ of consumers cease playing the game after an aggregate of around 6 days of gameplay, while $75 \%$ of consumers choose to stop playing the game after an aggregate of about 9 days. The largest recorded aggregate amount of time spent playing is over 8 million seconds or 94 full days (cf. Figure 3).

[Figure 3 about here]

Summary and descriptive statistics for all other relevant variables in our dataset can be found in Table 1. To reflect the distribution of role and vehicle use, we calculate a Herfindhal-Hershman Index (HHI) score for each consumer on a rolling (round-by-round) basis. Owing to the way in which the measure is calculated, consumers who only ever use a single role or vehicle will record a value of 1 for each of these measures, while those who use the full variety of each role or vehicle in each game round would record values of 0.25 (given the 4 available roles) or 0.167 (given the 6 available vehicles including 'on foot'). Thus, lower values for the respective $\mathrm{HHI}$ scores reflect a greater variety of use of roles and vehicles over the course of the player's engagement with the game.

\section{[Table 1 about here]}

Equation 1 specifies the aggregate amount of time spent playing the game as a function of consumer's (fixed) demographic characteristics, as well as round-byround (rolling) measures of the gaming experience and skill of the consumer $i$ at time $t$, as well as the in-game variety chosen by consumer $i$ at time $t$. The model also includes a number of individual and game characteristic controls. 


\section{TotalTimeSpent ${ }_{i t}=$}

$$
f\left(\text { Demographics }_{i t}, \text { GamingExpSkills }_{i t}, \text { In-GameVariety }_{i t}, \text { Controls }_{i t}\right)
$$

where TotalTimeSpent captures the aggregate amount of time each consumer $i$ devotes to their participation in the game. Demographics represents a vector of variables reflecting consumer i's age, gender, and home country. In addition, we add a quadratic age polynomial to control for any non-linear relationship with participation duration. GamingExpSkills represents a vector of variables reflecting gaming experience and skill, calculated on a rolling basis. This vector includes the difference between numbers of kills and deaths (i.e. the number of kills made by consumer $i$ subtracting the number of times consumer $i$ died, aggregated over all rounds up to time $t$ ) averaged over the aggregate number of seconds in which they have played the game. This vector also includes a measure of the non-combat score earned by consumer $i$ per second (i.e. the amount of points earned for all non-combat related activities, aggregated over all rounds up to time $t$ ), as well as the so-called 'rookie effect'; a dynamically calculated variable reflecting a consumer's lack of experience by counting the difference between the number of days since the launch date of the game and the number of days a consumer has already played the game as of time $t$. As we expect the rookie effect to have a non-linear relationship with overall gameplay duration, we also include a quadratic polynomial for this variable. Finally, the vector includes a measure of the consumer's rank at the start of each round, again calculated on a rolling basis. In-GameVariety is a vector of variables containing dynamically calculated $\mathrm{HHI}$ measures reflecting the variety of different roles adopted by consumer $i$ over all rounds up to time $t$ (i.e. Assault, Recon, Engineer, and Support), as well as the variety of vehicles used (i.e. armoured and unarmored land vehicles, jet, boat, and helicopter) over all rounds up to time $t$. The vector also includes a $\mathrm{HHI}$ measure representing variety 
in the use of game modes (e.g. Conquest, Rush or Team Death Match) selected by consumer $i$ over all rounds up to time $t$. Controls represents a vector of control variables that might also have affected the length of time that consumer $i$ spends participating in the game, such as the lifetime purchase amount of consumer $i$, as well as the hardware platform used by consumer $i$ to play the game.

We analyse the impact of these independent factors and their covariates on the aggregate amount of time spent participating in the game using duration analysis regressions. Duration models allow for censoring, owing the fact that play might continue beyond the end of our sample period. We measure 'failures' if we do not observe any further participation in gameplay rounds after the specific title became obsolete following the release of a direct sequel. The sequel was released on October 31, 2013. As the consumers in the second cohort started playing the game three month after the release, we assume that after additional three month the consumers have now switched to the newly released game title. Thus, we measure 'failures' if we do not observe participation in gameplay rounds after January 31,2014 . A majority of players in our sample $(1,296)$ demonstrate the criteria for failure, with the remaining 112 players continued playing right up to the end of our sample period. We focus on the survival function rather than on the hazard rate in order to better identify the consumer preferences that determine duration of gameplay experience. The aggregate amount of time that a consumer spends playing the game is considered a random variable $T$ with distribution function $F(t)=\operatorname{Prob}(T \leq t)$. The associated survival function gives the probability that a consumer continues to play the game after participating in a given round at time $t$ and is given by

$$
S(t)=1-F(t)=\operatorname{Prob}(T>t) .
$$

As $F$ is differentiable, the derivative or density function of the lifetime distribution is given by

$$
f(t)=F^{\prime}(t)=\frac{d}{d t} F(t)
$$


The survival function can thus be expressed in terms of the density function:

$$
S(t)=1-F(t)=\operatorname{Prob}(T>t)=\int_{t}^{\infty} f(u) d u .
$$

A well-used model for adjusting survival functions for the effects of covariates is the accelerated failure-time (AFT) model. In the AFT model, the natural logarithm of the survival time is defined as a linear function of the covariates and is expressed as follows:

$$
\ln t=x \beta+\gamma
$$

where $x$ is a vector of covariates, $\beta$ is a vector of regression coefficients, and $\gamma$ is the error with density $f($.$) .$

The distributional form of the error term determines the regression model. For example, if the $f($.$) follows a normal distribution, the lognormal regression model is$ obtained. If $f($.$) follows a logistic distribution, the loglogistic regression is obtained.$ Finally, if $f($.$) follows an extreme-value distribution, we yield the exponential and$ the Weibull regression models. It is standard practice to consider theoretical survival distributions that allow for a non-constant hazard rate. Thus, different survival studies include different survival distributions (e.g. De Vany and Walls (1997) and Deuchert et al. (2005) consider the Weibull distribution and Chisholm and Norman (2006) consider a log normal specification). Following Deuchert et al. (2005) and McKenzie (2009), we also consider the Weibull specification and extend the results with the exponential function.

\section{Results}

In this section of the paper, we present the results from a number of duration models to explain variations in the aggregate amount of time spent playing the game. The associated Kaplan-Meier survival function is plotted in Figure 3. The results from these parametric survival models are presented in Table 2. Specifically, spec- 
ifications (1) and (2) respectively present results from the Exponential and Weibull models, while specifications (3) and (4) present equivalent results using standardized variables. The estimations are mostly consistent and robust throughout all specifications.

[Table 2 about here]

With respect to hypothesis $\mathrm{H} 1$ relating to variations in preferences according to demographics, the duration models presented in Table 2 show that multiple individual-level characteristics associate significantly with the aggregate amount of time the consumer spends playing the game. Our coefficient estimates relating to consumer age suggest that, while the relationship between the two variables is positive, the negative quadratic term indicates a diminishing impact of increases in player age upon aggregate play time. Thus, even though age is shown to affect aggregate duration of gameplay, we reject Hypothesis $\mathrm{H} 1 \mathrm{a}$ given that the (positive) sign of the estimated coefficient is opposite to our predictions. Further, our results are mixed with respect to the effect of player gender upon the aggregate duration of gameplay. While the exponential model finds no statistically significant relationship between gender and aggregate play time, the Weibull models find evidence of a negative and statistically significant relationship. The latter finding is consistent with our prediction based on the relative lack of focus on achievement among female gamers observed by Yee (2006). However, we are therefore led to reject Hypothesis $\mathrm{H} 1 \mathrm{~b}$ given the inconsistency of findings between specifications. By contrast, our parameter estimates consistently show that country of residence significantly impacts upon aggregate gameplay durations, with relatively large and significant positive coefficients estimated for the more prevalent countries in the sample compared with players in other locations. This finding suggests that there are significant country and perhaps cultural variations in the duration of engagement with this particular video game, leading us to accept Hypothesis H1c. Taken together, these results demonstrate limited overall support for hypothesis $\mathrm{H} 1$. We 
find some evidence that consumer behaviour differs according to demographics, although several of the relevant coefficient estimates from our models are either found to be inconsistent between specifications or have the opposite sign to that which was expected.

With respect to hypothesis $\mathrm{H} 2$ relating to consumer experience and skill, the coefficient estimates for the 'rookie effect' suggest that consumers with a lack of experience who started playing longer and longer after the game's initial release are more likely to continue playing the game over longer periods. However, the negative and statistically significant quadratic term implies that the relationship between inexperience and aggregate gameplay duration suffers from diminishing returns. These findings are to be expected given that the likelihood of continued participation will eventually decline over a longer association with the game, possibly as players become bored over time. Indeed, players with low 'rookie effect' scores signed up to participate in the game very early in its life cycle, which implies that these games might be more likely to be 'early adopters' that would be more willing to switch to newer software titles as soon as they are released. By contrast to our rookie effect variable, the player's starting rank in each particular round offers a representation of the intensity of each player's participation over time given that higher ranked need to be 'earned' over time through gameplay achievements. The positive and statistically significant coefficient for this variable estimated in all specifications signals that gamers who participate more intensively are in turn more likely to continue playing over longer durations. We therefore find mixed evidence in support of $\mathrm{H} 2 \mathrm{a}$ given that 'rookies' are generally found to participate for longer durations, while players with higher ranks are found to participate for longer.

By contrast, the results also show strong evidence that a consumer's performance in terms of the difference between kills and deaths per second of play associates negatively with the aggregate amount of time spent participating in the game, although the positive quadratic term also implies diminishing returns in this relationship. Broadly speaking, consumers are more likely to continue playing the 
game when they die with greater frequency than they kill others. The same relationship is also observed for non-combat scores, although the standardized coefficients imply that the relationship is not so important as observed for combat-related activity. Therefore, we reject hypotheses $\mathrm{H} 2 \mathrm{~b}$ and $\mathrm{H} 2 \mathrm{c}$ due to the coefficient estimates being opposite to our predictions. Although these findings might seem counter-intuitive, they may in fact be consistent with our findings in relation to the rookie effect. As such, we conclude that players are more likely to continue playing the game at the early stages of their engagement when their skill levels are low and they are killed with greater frequency than they kill others. As that relationship starts to change and players gain in skill and experience such that they 'master' the game, we interpret these findings to suggest that the player might become bored and seek a fresh challenge or experience elsewhere. Thus, despite the unexpected coefficient estimates for some variables, our overall findings offer support for hypothesis $\mathrm{H} 2$ and suggest that individual skill and experience levels are significantly related to aggregate gameplay duration.

In relation to hypothesis $\mathrm{H} 3$ concerning variety on in-game experience, the negative and statistically significant coefficients estimated for the HHIs suggests that a wider variety in the use of roles and vehicles associates with significantly longer aggregate play durations. The former coefficient estimate is larger in absolute magnitude than the latter, indicating that variety in the use of roles is a more important determinant of aggregate play duration than variety in the use of vehicles. This leads us to accept both hypotheses $\mathrm{H} 3 \mathrm{a}$ and $\mathrm{H} 3 \mathrm{~b}$. However, the positive and statistically significant coefficient estimates associated with the $\mathrm{HHI}$ representing the use of game modes implies that consumers are more likely to play for longer durations when they play in a smaller variety of modes. We therefore reject hypothesis $\mathrm{H} 2 \mathrm{c}$, implying that consumers prefer to specialise in the type of game mode they adopt, although the smaller magnitude of the coefficient estimates imply that it is a less important determinant of play duration than variety in the use of both vehicles and roles. Taken together, these findings offer broad support for hypothe- 
sis $\mathrm{H} 3$ given that consumers demonstrate a preference for variety in terms of their use of roles and vehicles, although appear to exhibit the opposite preference when it comes to game modes.

In addition to the variables that explicitly allow us to test our research hypotheses, we also include a number of controls in the model specifications presented in Table 2. Our control variables reflecting the hardware platform used by each individual consumer suggests a degree of heterogeneity in duration across platforms, with Xbox users suggested to play for slightly longer durations than PC or PS3 users. Our control variable capturing the lifetime monetary purchase amounts of each consumer within the specific online gaming environment under study shows a relatively weak negative association with the dependent variable, implying that monetary expenditures within the game have a limited impact on the duration of consumer engagement. Finally, our variable reflecting the sign up date for their online gaming account with the publisher implies that those who have held accounts for longer periods are less likely to continue playing for longer durations. This finding is consistent with our findings relating to the rookie effect and support the contention that longer-standing players will be more likely to cease playing the game at any moment in time.

Overall, these results help shed considerable light on the preferences and behaviours of individual video game consumers. We observe some support for hypothesis $\mathrm{H} 1$ along with stronger support for hypotheses $\mathrm{H} 2$ and $\mathrm{H} 3$. In the broadest sense, our evidence suggests that consumer experience, skills and in-game variety have a more significant effect on patterns of gameplay than demographics. We find these results to be reasonably consistent between the different duration models. However, the signs of several coefficient estimates are contrary to our initial expectations, most notably those relating age, experience and the difference between kills and deaths. We discuss the possible interpretations and implications of these findings below. 


\section{Concluding Remarks and Managerial Implications}

This study undertakes a large-scale analysis of recorded behaviours in order to investigate consumer preferences and determinants of video game consumption. We identify a number of consumer and gameplay traits (i.e. demographics, experience and skill, and variety) to explain video game consumption that are consistent with prior studies using U\&G theory. More specifically, we use these traits to model variations in the aggregate amount of time spent playing the game at level of the individual consumer. Given that the existing literature has only partially examined the drivers of consumer engagement with multiplayer video games (Wu et al. 2010), this work makes a unique contribution by providing the first empirical evidence on the basis of the modelling of observed behaviours and preferences. We show that country of residence and variety in the range of different roles or vehicles has the greatest effect upon the likelihood of longer participation with the game. We also find that more experienced gamers who have been playing the game for longer are less likely to continue playing the game at any given point in time. We take this to be indicative of more experienced consumers having mastered the game and eventually becoming bored and moving on to a fresh challenge by playing a different game.

Our finding relating to the role of consumer experience may at first seem counterintuitive, but we believe it is at least somewhat consistent with predictions and findings from the U\&G model in terms of the motivating influence of challenge and player achievement (Yee 2006). In addition, our findings relating to variety in the use of different player roles and vehicles is consistent with the U\&G model's suggestion that maintaining consumer interest and offering new experiences are important motivations for sustained consumer participation (Jansz and Tanis 2007). We further contend that this finding offers empirical support for the findings of Davis et al. (2013), who show that the usage of video games is better explained by variations in hedonic motivations than by utilitarian factors. Hedonic motivations 
mean that players desire to be entertained, to have fun and to be immersed in the experience. Hedonic factors that influence the usage are self-congruity (Davis and Lang 2013) or self-efficacy (Davis and Lang 2011). Our findings suggest that hedonic factors, e.g. playing different roles or driving different vehicles, associate positively with the likelihood of longer aggregate play durations. By contrast, utilitarian consumption is more task-oriented and follows specific rules, with specific utilitarian factors being found to have no significant impact on video game usage (Davis and Lang 2012). In our study, game modes represent utilitarian factors given their task orientation, with the negative association we find with aggregate play duration being consistent with these broader theoretical expectations.

Video games are high-involvement products with multi-platform and multiplayer characteristics whose prime aim is to provide a positive game experience and consequently ensure consumption of their customers (Anderson et al. 1994). Our findings clearly show that consumers with more experience are less likely to continue playing for longer durations at any given point in time. Our interpretation of this finding is that players who master the game over longer periods will eventually become bored and cease playing, perhaps seeking a new experience or moving on to a play a different game. To achieve sustained player engagement in such situations, companies might better be able to retain players through offering a wider range of expansion packs and premium or additional content (DavidoviciNora 2014). Such strategies might ultimately lead to the evolution of individual software titles into viable content delivery platforms that would retain players over longer periods. Video game developers can make use of these platforms to sell complementary add-on and premium services, but have to carefully consider how to incentivize consumer engagement (Cheung et al. 2015).

In addition, the strong, positive association between duration of participation and the use of many different roles and vehicles indicates that game designers should prioritise the availability of a wide variety of customisation options to expose consumers to greater variety and encourage different ways in which to approach 
the game. This relationship has already been shown in Multiplayer Online Battle Arena (MOBA) games (e.g. Myślak and Deja 2015). MOBAs are considered eSports, whereby two teams engage in combat with the help of a chosen avatar, often called a 'champion'. Popular MOBA games include titles such as League of Legends and Dota2. Myślak and Deja (2015) show that the consideration of players' preferences over roles or champions in LoL would improve the chances of winning by $65 \%$. Modern online multiplayer games are characterised by offering strategic decision making in addition to skill-based combat (Chen et al. 2016). Thus, developers also need to ensure that the available options are sufficiently well balanced and interdependent so as to encourage greater variety in their adoption by players. Our findings in this regard are also consistent with Choi and Kim (2004), who find evidence of increased customer loyalty in the presence of greater opportunities to select and customise character abilities.

A limitation of our study in terms of its contribution to U\&G theory is that our large scale, data-driven study does not allow us to examine the more subjective motivations highlighted by the model, most notably social interaction, as well as other potential motivations such as excitement, arousal and immersion. Future studies could overcome this limitation by adopting a hybrid approach, whereby experimental or survey data of the kind gathered by Sherry et al. (2006) and Davis et al. (2013) are combined with recorded patterns of video game engagement similar to those used in our study. Although this approach might lead to a reduction in the size of data sample, it could also lead to an outcome that offers the 'best of both worlds', whereby subjective assessments and emotions could be measured and compared against actual rather than stated patterns of consumption. In addition, our study relies on data from a single online first-person shooter game primarily based around player-versus-player combat. Future research could acquire data from a number of different software titles across platforms and genres to ascertain the applicability of our findings in different contexts. Additionally, the consumer preferences studied in this research are shown to be somewhat time- 
variant. Thus, future studies could further analyse data on consumer behaviour over a longer time horizon to explore how preferences might change over time. The latter point is particularly relevant given the rapidly changing video game environment and market for technology goods.

\section{References}

Abbasi, A. Z. and Jamak, A. B. S. A. (2017). Playful-consumption experience of videogame-play influences consumer video-game engagement: A conceptual model. Global Business and Management Research, 9(1s):244.

Activision Publishing Inc. (2011). Call of duty modern warfare 3 hits $\$ 1 \mathrm{bn}$ milestone in just 16 days. Retrieved from: http://investor.activision.com/releasedetail.cfm?ReleaselD=632389 (visited on $7 / 6 / 17)$.

Anderson, E. W., Fornell, C., and Lehmann, D. R. (1994). Customer satisfaction, market share, and profitability: Findings from Sweden. Journal of Marketing, 58(3):pp. 53-66.

Bandura, A. (2001). Social cognitive theory: An agentic perspective. Annual Review of Psychology, 52(1):1-26.

Borowiecki, K. J. and Prieto-Rodriguez, J. (2015). Video games playing: A substitute for cultural consumptions? Journal of Cultural Economics, 39(3):239-258.

Buchanan-Oliver, M. and Seo, Y. (2012). Play as co-created narrative in computer game consumption: The hero's journey in warcraft iii. Journal of Consumer Behaviour, 11(6):423-431.

Chang, B.-H., Lee, S.-E., and Kim, B.-S. (2006). Exploring factors affecting the adoption and continuance of online games among college students in south 
korea integrating uses and gratification and diffusion of innovation approaches. New Media \& Society, 8(2):295-319.

Chen, Z., Sun, Y., El-Nasr, M. S., and Nguyen, T. D. (2016). Player skill decomposition in multiplayer online battle arenas. In Meaningful Play.

Cheung, C. M., Shen, X.-L., Lee, Z. W., and Chan, T. K. (2015). Promoting sales of online games through customer engagement. Electronic Commerce Research and Applications, 14(4):241 - 250. Special section on e-selling and online engagement.

Chisholm, D. C. and Norman, G. (2006). When to exit a product: Evidence from the U.S. motion-picture exhibition market. American Economic Review, 96(2):5761.

Choi, D. and Kim, J. (2004). Why people continue to play online games: In search of critical design factors to increase customer loyalty to online contents. CyberPsychology \& Behavior, 7(1):11-24.

Cox, J. (2008). Purchasing power parity and cultural convergence: Evidence from the global video games market. Journal of Cultural Economics, 32(3):201-214.

Davidovici-Nora, M. (2014). Paid and free digital business models innovations in the video game industry. Digiworld Economic Journal, 94(2):83-102.

Davis, R. and Lang, B. (2011). Modeling game usage and purchase behaviour: the consumption value of self efficacy. Journal of Retailing and Consumer Services, 19(1):67-77.

Davis, R. and Lang, B. (2012). Does perceived control increase game usage and purchase behaviour? International Journal of Consumer Research, 1(1):47-69.

Davis, R. and Lang, B. (2013). Does game self-congruity increase usage and purchase? Young Consumers, 14(1):52-66. 
Davis, R., Lang, B., and Gautam, N. (2013). Modeling utilitarian-hedonic dual mediation (uhdm) in the purchase and use of games. Internet Research, 23(2):229256.

De Grove, F., Cauberghe, V., and Van Looy, J. (2016). Development and validation of an instrument for measuring individual motives for playing digital games. Media Psychology, 19(1):101-125.

De Vany, A. S. and Walls, W. D. (1997). The market for motion pictures: Rank, revenue, and survival. Economic Inquiry, 35(4):783-797.

Deuchert, E., Adjamah, K., and Pauly, F. (2005). For oscar glory or oscar money? Journal of Cultural Economics, 29(3):159-176.

Holbrook, M. B., Chestnut, R. W., Oliva, T. A., and Greenleaf, E. A. (1984). Play as a consumption experience: The roles of emotions, performance, and personality in the enjoyment of games. Journal of Consumer Research, 11(2):728-739.

Jansz, J. and Tanis, M. (2007). Appeal of playing online first person shooter games. CyberPsychology \& Behavior, 10(1):133-136.

Kuo, A., Hiler, J. L., and Lutz, R. J. (2017). From Super Mario to Skyrim: A framework for the evolution of video game consumption. Journal of Consumer Behaviour, 16(2):101-120.

LaRose, R., Lin, C. A., and Eastin, M. S. (2003). Unregulated internet usage: Addiction, habit, or deficient self-regulation? Media Psychology, 5(3):225-253.

Lee, D. and LaRose, R. (2007). A socio-cognitive model of video game usage. Journal of Broadcasting \& Electronic Media, 51(4):632-650.

Liu, D., Li, X., and Santhanam, R. (2013). Digital games and beyond: What happens when players compete. MIS Quarterly, 37(1):111-124. 
McKenzie, J. (2009). Revealed word-of-mouth demand and adaptive supply: survival of motion pictures at the Australian box office. Journal of Cultural Economics, 33(4):279-299.

Myślak, M. and Deja, D. (2015). Developing game-structure sensitive matchmaking system for massive-multiplayer online games. In Aiello, M. L. and McFarland, D., editors, Social Informatics: Soclnfo 2014 International Workshops, Barcelona, Spain, November 11, 2014, Revised Selected Papers, pages 200-208. Springer International Publishing, Cham.

Przybylski, A. K., Rigby, C. S., and Ryan, R. M. (2010). A motivational model of video game engagement. Review of General Psychology, 14(2):154.

Sherry, J. L., Lucas, K., Greenberg, B. S., and Lachlan, K. (2006). Video game uses and gratifications as predictors of use and game preference. Playing video games: Motives, responses, and consequences, 24:213-224.

Statista (2017). Value of the video game market in the United States from 2011 to 2020 (in million U.S. dollars). Retrieved from: https://www.statista.com/statistics/246892/value-of-the-video-game-marketin-the-us (visited on 7/6/17).

Tamborini, R., Bowman, N. D., Eden, A., Grizzard, M., and Organ, A. (2010). Defining media enjoyment as the satisfaction of intrinsic needs. Journal of Communication, 60(4):758-777.

Wallenius, M., Rimpela, A., Punamaki, R.-L., and Lintonen, T. (2009). Digital game playing motives among adolescents: Relations to parent-child communication, school performance, sleeping habits, and perceived health. Journal of Applied Developmental Psychology, 30(4):463-474.

Weibull, L. (1985). Structural factors in gratifications research. Media gratifications research: Current perspectives, pages 123-147. 
Wu, J.-H., Wang, S.-C., and Tsai, H.-H. (2010). Falling in love with online games: The uses and gratifications perspective. Computers in Human Behavior, 26(6):1862-1871.

Yee, N. (2006). Motivations for play in online games. CyberPsychology \& Behavior, $9(6): 772-775$. 


\section{A Appendix: Tables}

Table 1 Key Descriptive Statistics for Variables Used in the Empirical Analysis

\begin{tabular}{|c|c|c|c|c|c|c|}
\hline Variable & Description & Obs & Mean & Std. Dev. & Min & Max \\
\hline \multicolumn{7}{|l|}{ Dependent Variables } \\
\hline Total Time Spent & $\begin{array}{l}\text { Total time a consumer has spent with the game (in sec- } \\
\text { onds). }\end{array}$ & 728811 & 593433 & 885646.2 & 1.74 & 8156442 \\
\hline Age & The consumer's age. & 728811 & 30.432 & 9.438 & 15 & 80 \\
\hline Gender (Female Consumers) & The consumer's gender with 1="female". & 728811 & .004 & .06 & 0 & 1 \\
\hline & Consumers living in the U.S. with 1="U.S.". & 728811 & .324 & .468 & 0 & 1 \\
\hline \multicolumn{7}{|l|}{ Experience and Skills } \\
\hline Rookie Effect & $\begin{array}{l}\text { Difference between the number of days a consumer has } \\
\text { played the game and the launch date. }\end{array}$ & 728811 & 181.262 & 157.223 & 2 & 843 \\
\hline Starting Rank & The consumer's starting rank at the beginning of the round. & 728811 & 50.908 & 34.478 & 0 & 145 \\
\hline $\begin{array}{l}\text { Difference (Kills-Deaths) per Sec- } \\
\text { ond }\end{array}$ & $\begin{array}{l}\text { The difference between the number of kills and deaths } \\
\text { made by the consumer per second in the round. }\end{array}$ & 728811 & .001 & .038 & -1 & 4.425 \\
\hline Non-Combat Score per Second & $\begin{array}{l}\text { Score earned by a consumer per second in a given round } \\
\text { derived from non-combat. }\end{array}$ & 728811 & 3.668 & 14.306 & 0 & 1000 \\
\hline \multicolumn{7}{|l|}{ In-Game Variety } \\
\hline $\mathrm{HHI}$ Number of Roles & $\begin{array}{l}\text { Herfindhal-Hershman-Index of the number of different roles } \\
\text { played in the previous rounds by a consumer }\end{array}$ & 728811 & .347 & .124 & .25 & 1 \\
\hline HHI Number of Vehicles & $\begin{array}{l}\text { Herfindhal-Hershman-Index of the number of different vehi- } \\
\text { cles used in the previous rounds by a consumer }\end{array}$ & 728811 & .401 & .176 & .18 & 1 \\
\hline HHI Game Modes & $\begin{array}{l}\text { Herfindhal-Hershman-Index of the different game modes } \\
\text { played in the previous rounds by a consumer }\end{array}$ & 728811 & .547 & .193 & .25 & 1 \\
\hline
\end{tabular}


Table 1 Key Descriptive Statistics for Variables Used in the Empirical Analysis

\begin{tabular}{|c|c|c|c|c|c|c|}
\hline Variable & Description & Obs & Mean & Std. Dev. & Min & Max \\
\hline \multicolumn{7}{|l|}{ Controls } \\
\hline Hardware Platform (PC) & $\begin{array}{l}\text { Consumers using a PC as the gaming platform with } 1=\text { "PC } \\
\text { usage". }\end{array}$ & 728811 & .24 & .427 & 0 & 1 \\
\hline Hardware Platform (PS3) & $\begin{array}{l}\text { Consumers using a Sony PS3 as the gaming platform with } \\
1=\text { "PS3 usage". }\end{array}$ & 728811 & .379 & .485 & 0 & 1 \\
\hline Hardware Platform (XBOX) & $\begin{array}{l}\text { Consumers using a Microsoft XBOX } 360 \text { as the gaming } \\
\text { platform with } 1=\text { "XBOX usage". }\end{array}$ & 728811 & .38 & .486 & 0 & 1 \\
\hline Cohort 1 & $\begin{array}{l}\text { Designates whether a consumer belongs to cohort } 1 \text { (con- } \\
\text { sumers started playing the game in the first month after the } \\
\text { launch) or cohort } 2 \text { (consumers started playing after three } \\
\text { month) with } 1=\text { "cohort } 1 \text { ". }\end{array}$ & 728811 & .568 & .495 & 0 & 1 \\
\hline Lifetime Purchase Amount & $\begin{array}{l}\text { How much, in USD, the consumer has spent with the com- } \\
\text { pany as of the time the data was pulled (March } 4,2014 \text { ) }\end{array}$ & 728811 & 42.099 & 178.536 & 0 & 3289.028 \\
\hline Consumer's Signup Date & $\begin{array}{l}\text { Date on which the consumer opened an account with the } \\
\text { company }\end{array}$ & 728811 & 18475.01 & 510.329 & 15612 & 19023 \\
\hline
\end{tabular}


Table 2 Duration Model Specifications for the Total Time a Consumer Spends with the Game

DEPENDENT VARIABLE:

TOTAL TIME PLAYED IN SECONDS

\begin{tabular}{|c|c|c|c|c|}
\hline $\begin{array}{l}\text { INDEPENDENT } \\
\text { VARIABLES }\end{array}$ & $\begin{array}{l}(1) \\
\text { Exponential }\end{array}$ & $\begin{array}{c}(2) \\
\text { Weibull }\end{array}$ & $\begin{array}{l}(3) \\
\text { Exponential } \\
\quad \text { (standardizec }\end{array}$ & $\begin{array}{c}(4) \\
\text { Weibull } \\
\text { ariables) }\end{array}$ \\
\hline \multicolumn{5}{|l|}{ Demographics } \\
\hline Age & $\begin{array}{l}0.027^{* \star *} \\
(0.001)\end{array}$ & $\begin{array}{l}0.032^{* * *} \\
(0.000)\end{array}$ & $\begin{array}{l}0.251^{\star \star \star} \\
(0.006)\end{array}$ & $\begin{array}{l}0.298^{\star * \star} \\
(0.004)\end{array}$ \\
\hline $\mathrm{Age}^{2}$ & $\begin{array}{l}-0.000^{\star \star *} \\
(0.000)\end{array}$ & $\begin{array}{l}-0.000^{* * *} \\
(0.000)\end{array}$ & $\begin{array}{l}-0.146^{\star * *} \\
(0.006)\end{array}$ & $\begin{array}{l}-0.173^{\star \star \star} \\
(0.004)\end{array}$ \\
\hline Gender (Female) & $\begin{array}{r}0.020 \\
(0.020)\end{array}$ & $\begin{array}{l}-0.106^{\star * *} \\
(0.011)\end{array}$ & $\begin{array}{r}0.020 \\
(0.020)\end{array}$ & $\begin{array}{l}-0.106^{\star * *} \\
(0.011)\end{array}$ \\
\hline Country GB & $\begin{array}{l}0.765^{\star * *} \\
(0.075)\end{array}$ & $\begin{array}{l}0.900^{* * *} \\
(0.043)\end{array}$ & $\begin{array}{l}0.765^{\star \star *} \\
(0.075)\end{array}$ & $\begin{array}{l}0.900^{\star * *} \\
(0.043)\end{array}$ \\
\hline Country Japan & $\begin{array}{l}0.745^{\star \star *} \\
(0.075)\end{array}$ & $\begin{array}{l}0.938^{* * *} \\
(0.043)\end{array}$ & $\begin{array}{l}0.745^{\star \star \star} \\
(0.075)\end{array}$ & $\begin{array}{l}0.938^{\star \star \star} \\
(0.043)\end{array}$ \\
\hline Country Russia & $\begin{array}{l}0.720^{\star \star \star *} \\
(0.076)\end{array}$ & $\begin{array}{l}0.846^{\star * \star} \\
(0.043)\end{array}$ & $\begin{array}{l}0.720^{\star \star \star} \\
(0.076)\end{array}$ & $\begin{array}{l}0.846^{\star * *} \\
(0.043)\end{array}$ \\
\hline Country US & $\begin{array}{l}0.749^{\star * *} \\
(0.075)\end{array}$ & $\begin{array}{l}0.888^{* * *} \\
(0.043)\end{array}$ & $\begin{array}{l}0.749^{\star \star \star} \\
(0.075)\end{array}$ & $\begin{array}{l}0.888^{\star * *} \\
(0.043)\end{array}$ \\
\hline \multicolumn{5}{|l|}{ Experience and Skills } \\
\hline Rookie Effect & $\begin{array}{l}0.003^{* * *} \\
(0.000)\end{array}$ & $\begin{array}{l}0.003^{* * *} \\
(0.000)\end{array}$ & $\begin{array}{l}0.255^{\star \star \star} \\
(0.002)\end{array}$ & $\begin{array}{l}0.295^{\star * *} \\
(0.001)\end{array}$ \\
\hline Rookie Effect ${ }^{2}$ & $\begin{array}{l}-0.000^{\star \star *} \\
(0.000)\end{array}$ & $\begin{array}{l}-0.000^{* * *} \\
(0.000)\end{array}$ & $\begin{array}{l}-0.079^{* \star *} \\
(0.001)\end{array}$ & $\begin{array}{l}-0.097^{* * *} \\
(0.001)\end{array}$ \\
\hline Starting Rank & $\begin{array}{l}0.034^{\star * *} \\
(0.000)\end{array}$ & $\begin{array}{l}0.031^{* * *} \\
(0.000)\end{array}$ & $\begin{array}{l}1.170^{\star \star *} \\
(0.002)\end{array}$ & $\begin{array}{l}1.072^{\star \star \star} \\
(0.001)\end{array}$ \\
\hline Difference (Kills-Deaths) per & $-0.635^{\star \star *}$ & $-0.302^{\star \star \star}$ & $-0.024^{\star \star \star}$ & $-0.012^{\star \star *}$ \\
\hline Second & $(0.034)$ & $(0.019)$ & $(0.001)$ & $(0.001)$ \\
\hline Difference (Kills-Deaths) per & $0.087^{\star \star *}$ & $0.029^{\star *}$ & $0.000^{\star \star *}$ & $0.000^{\star *}$ \\
\hline Second $^{2}$ & $(0.023)$ & $(0.012)$ & $(0.000)$ & $(0.000)$ \\
\hline Non Combat Score per Second & $\begin{array}{l}-0.000^{\star \star \star} \\
(0.000)\end{array}$ & $\begin{array}{l}-0.001^{* * *} \\
(0.000)\end{array}$ & $\begin{array}{l}-0.007^{\star * *} \\
(0.002)\end{array}$ & $\begin{array}{l}-0.013^{\star * *} \\
(0.001)\end{array}$ \\
\hline Non Combat Score per Second ${ }^{2}$ & $\begin{array}{c}0.000^{\star \star \star *} \\
(0.000)\end{array}$ & $\begin{array}{l}0.000^{* * *} \\
(0.000)\end{array}$ & $\begin{array}{l}0.000^{* * *} \\
(0.000)\end{array}$ & $\begin{array}{l}0.000^{\star * *} \\
(0.000)\end{array}$ \\
\hline \multicolumn{5}{|l|}{ In-Game Variety } \\
\hline $\mathrm{HHI}$ Number of Roles & $\begin{array}{l}-1.092^{\star * *} \\
(0.011)\end{array}$ & $\begin{array}{l}-1.140^{\star * *} \\
(0.006)\end{array}$ & $\begin{array}{l}-0.135^{\star \star *} \\
(0.001)\end{array}$ & $\begin{array}{l}-0.141^{\star * *} \\
(0.001)\end{array}$ \\
\hline $\mathrm{HHI}$ Number of Different Vehicles & $\begin{array}{l}-0.714^{\star * *} \\
(0.007)\end{array}$ & $\begin{array}{l}-0.572^{* * *} \\
(0.004)\end{array}$ & $\begin{array}{l}-0.126^{\star \star *} \\
(0.001)\end{array}$ & $\begin{array}{l}-0.101^{* * *} \\
(0.001)\end{array}$ \\
\hline HHI Game Modes & $\begin{array}{c}0.086^{\star * *} \\
(0.007)\end{array}$ & $\begin{array}{c}0.131^{* * *} \\
(0.004)\end{array}$ & $\begin{array}{c}0.017^{\star \star *} \\
(0.001)\end{array}$ & $\begin{array}{c}0.025^{\star * *} \\
(0.001)\end{array}$ \\
\hline
\end{tabular}


Table 2 Duration Model Specifications for the Total Time a Consumer Spends with the Game

DEPENDENT VARIABLE:

TOTAL TIME PLAYED IN SECONDS

\begin{tabular}{|c|c|c|c|c|}
\hline $\begin{array}{l}\text { INDEPENDENT } \\
\text { VARIABLES }\end{array}$ & $\begin{array}{c}(1) \\
\text { Exponential }\end{array}$ & $\begin{array}{l}(2) \\
\text { Weibull }\end{array}$ & $\begin{array}{l}\text { (3) } \\
\text { Exponential } \\
\text { (standardized }\end{array}$ & $\begin{array}{c}(4) \\
\text { Weibull } \\
\text { ariables) }\end{array}$ \\
\hline \multicolumn{5}{|l|}{ Controls } \\
\hline Platform (PS3) & $\begin{array}{l}-0.005 \\
(0.004)\end{array}$ & $\begin{array}{l}0.024^{* * *} \\
(0.002)\end{array}$ & $\begin{array}{l}-0.005 \\
(0.004)\end{array}$ & $\begin{array}{l}0.024^{* * \star} \\
(0.002)\end{array}$ \\
\hline Platform (XBOX) & $\begin{array}{l}0.061^{\star * *} \\
(0.004)\end{array}$ & $\begin{array}{l}0.071^{* \star \star} \\
(0.002)\end{array}$ & $\begin{array}{l}0.061^{* \star *} \\
(0.004)\end{array}$ & $\begin{array}{l}0.071^{* * *} \\
(0.002)\end{array}$ \\
\hline Lifetime Purchase Amount & $\begin{array}{l}-0.000^{\star * *} \\
(0.000)\end{array}$ & $\begin{array}{l}-0.000^{\star \star \star} \\
(0.000)\end{array}$ & $\begin{array}{l}-0.015^{\star \star \star} \\
(0.001)\end{array}$ & $\begin{array}{l}-0.016^{* \star \star} \\
(0.001)\end{array}$ \\
\hline Cohort (Reference: Cohort 1) & $\begin{array}{l}-0.055^{\star * *} \\
(0.003)\end{array}$ & $\begin{array}{l}-0.078^{* * *} \\
(0.002)\end{array}$ & $\begin{array}{l}-0.055^{\star * *} \\
(0.003)\end{array}$ & $\begin{array}{l}-0.078^{* \star \star} \\
(0.002)\end{array}$ \\
\hline Account Signup Date & $\begin{array}{l}0.000^{\star * *} \\
(0.000)\end{array}$ & $\begin{array}{l}0.000^{\star \star \star} \\
(0.000)\end{array}$ & $\begin{array}{l}0.068^{\star * *} \\
(0.001)\end{array}$ & $\begin{array}{l}0.068^{\star \star \star} \\
(0.001)\end{array}$ \\
\hline Constant & $\begin{array}{l}7.340^{* * *} \\
(0.090)\end{array}$ & $\begin{array}{l}7.216^{* * *} \\
(0.051)\end{array}$ & $\begin{array}{l}11.899^{* * *} \\
(0.075)\end{array}$ & $\begin{array}{l}11.866^{* \star \star} \\
(0.043)\end{array}$ \\
\hline Observations & 728,811 & 728,811 & 728,811 & 728,811 \\
\hline No. of Consumers & 1,408 & 1,408 & 1,408 & 1,408 \\
\hline No. of Quitting Consumers & 1,296 & 1,296 & 1,296 & 1,296 \\
\hline
\end{tabular}

Robust standard errors in parentheses ${ }^{* \star *} p<0.01,{ }^{\star *} p<0.05,{ }^{*} p<0.1$

We included and controlled for 54 country dummies but decided to show only the four biggest video game markets (regarding game revenues). 


\section{B Appendix: Figures}

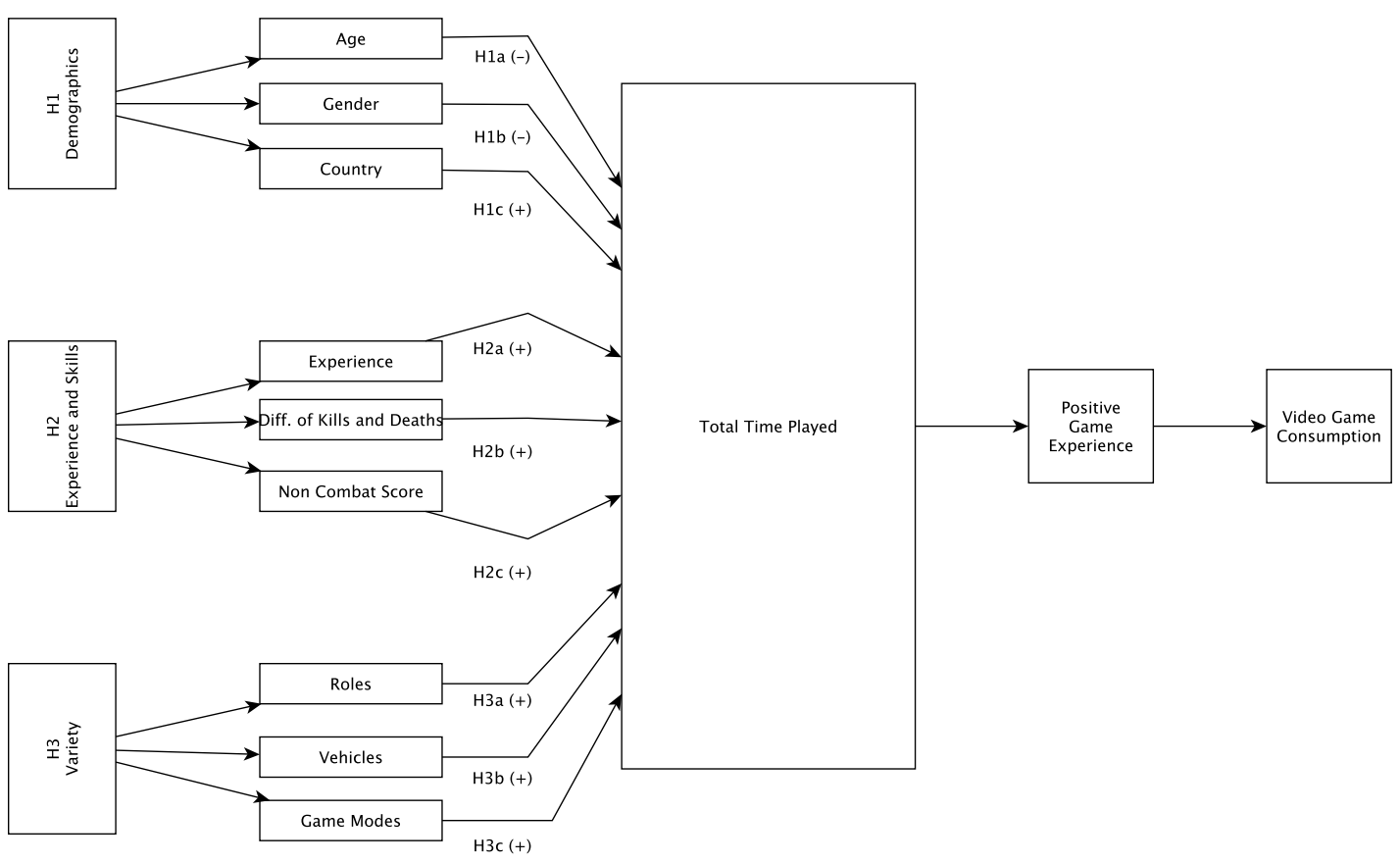

Figure 1 Conceptual Framework

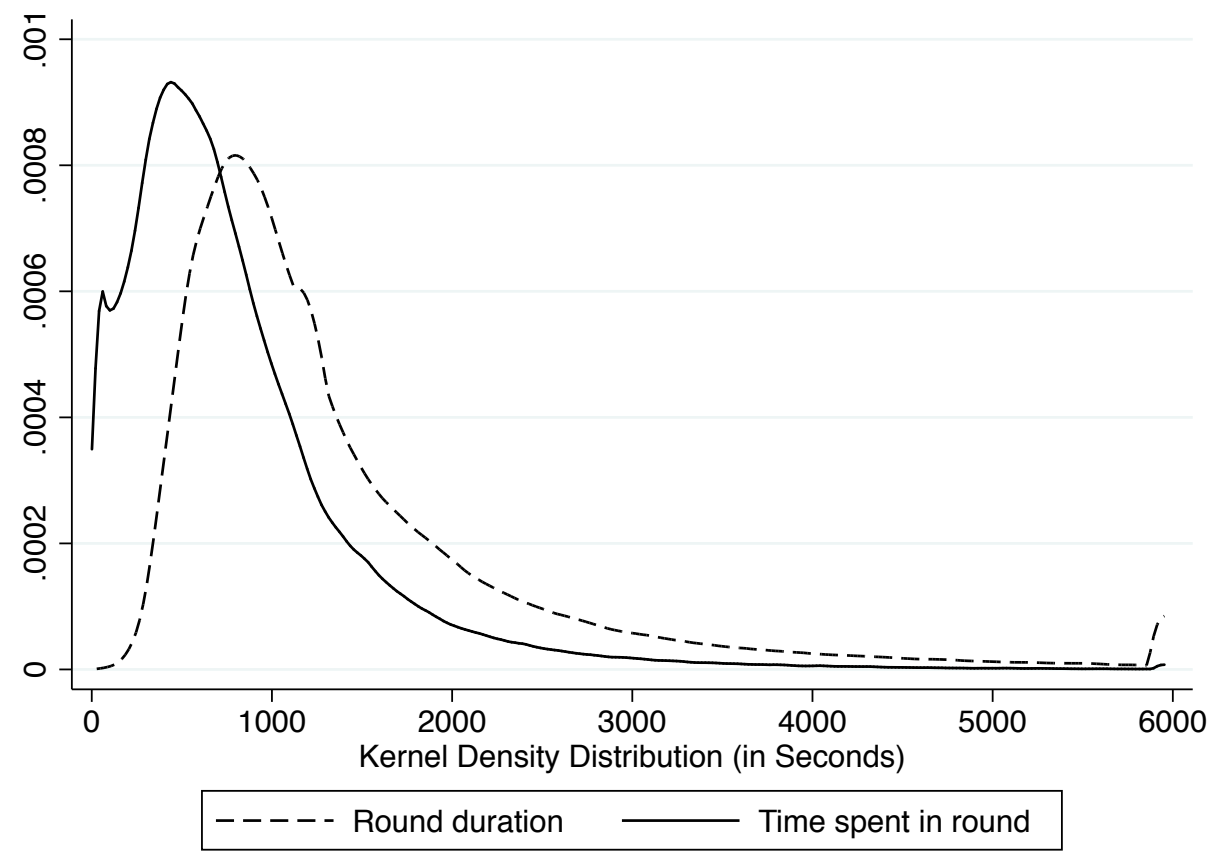

Figure 2 Density Distribution of Round Duration and Time Spent in Round (in seconds) 


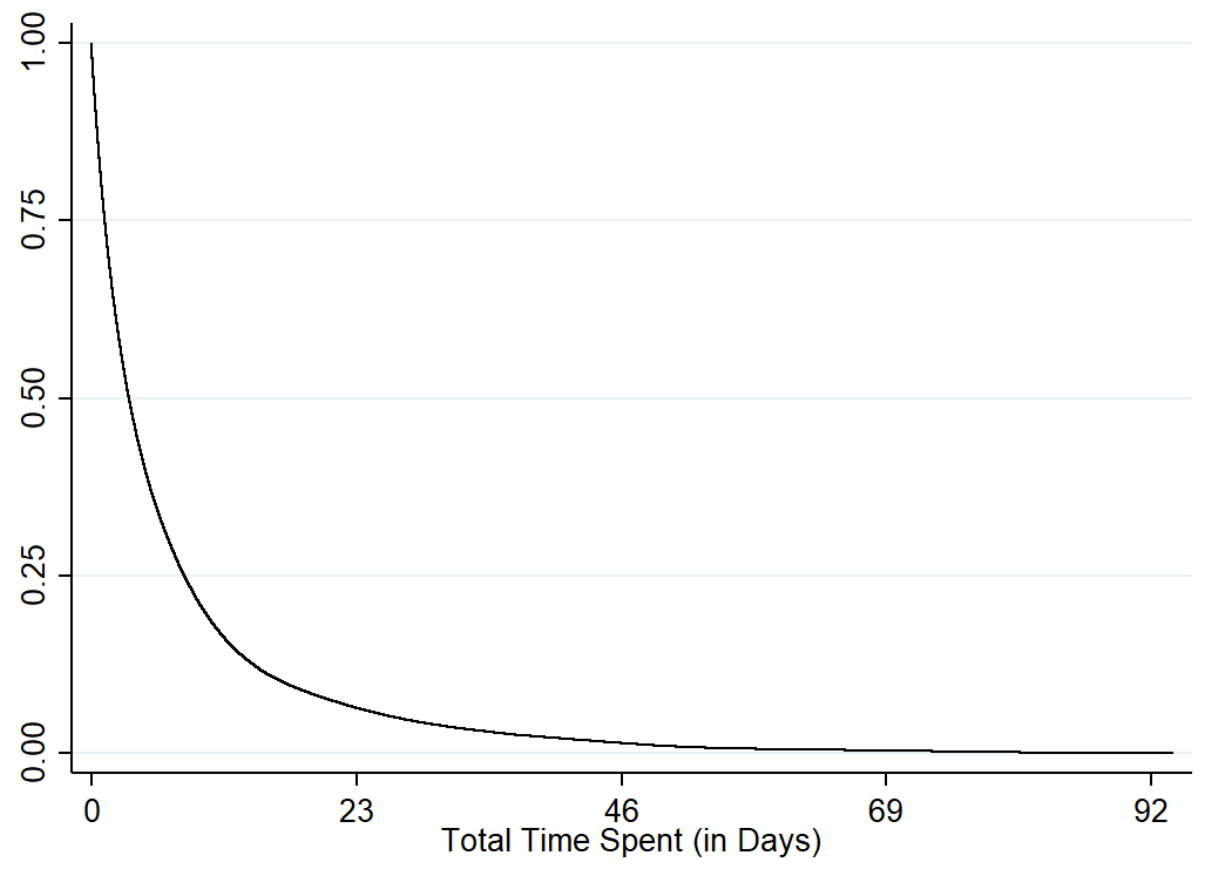

Figure 3 Total Time the Consumers Spend Playing the Game 